\title{
Using the Integration of QFD and IDEF Techniques for Mobile Wireless Classroom Process Improvement
}

\author{
Rungchat Chompu-inwai, Toni L. Doolen \\ Department of Industrial and Manufacturing Engineering \\ Oregon State University \\ Corvallis, Oregon, 97331-2407 \\ Phone: 1.541.737.2365 Fax: 1.541.737.5241 \\ E-mail address: toni.doolen@orst.edu.
}

\section{Introduction}

ABET 2004-2005 criteria for accrediting engineering programs require that institutions assure quality and foster the systematic pursuit of improvement in the quality of engineering education, satisfying the needs of constituencies in a dynamic and competitive environment ${ }^{1}$. Each engineering program seeking accreditation must have in place a process based on the needs of the program's various constituencies in which the objectives are determined and evaluated ${ }^{1}$. For this purpose, a systematic approach for educational process improvement and reengineering is needed.

Quality Function Deployment (QFD) is a quality improvement tool for determining customer requirements and translating them into product or service specifications. QFD has been applied for extracting customer requirements, as well as for designing elements based on those requirements in both university settings and other educational institutions in previous studies $^{2,3,4,5}$. However, only the question of what is needed to achieve the requirements is answered. The question of how the design elements or requirements can be achieved is unanswered. Integrated Definition Language $0\left(\mathrm{IDEF}_{0}\right)$ functional modeling is a structured approach for system design and analysis and can be used to answer these questions. With the use of $\mathrm{IDEF}_{0}$, functions, inputs, as well as mechanisms that are required to get the desired outputs under specific constraints can be identified.

This paper explores the complementary use of two different engineering modeling tools in describing educational processes associated with mobile wireless technology (MWT) classrooms. QFD and $\mathrm{IDEF}_{0}$ are integrated to determine the requirements and to specify the processes of the mobile wireless classroom. For this study, mobile wireless classrooms are defined as classrooms where MWT (e.g. personal digital assistants (PDA's), laptops and other customized devices with wireless capabilities) have been used with the goal of improving teaching processes and learning. The methodology presented in this paper provides a comprehensive framework for process improvement and reengineering. A specific application of this methodology was used to compare MWT classrooms in Industrial and Manufacturing Engineering (IME) at Oregon State University (OSU) with non-MWT classrooms. This was completed to illustrate how the methodology could be applied.

"Proceedings of the 2005 American Society of Engineering Education Annual Conference \& Exposition Copyright (C) 2005, American Society for Engineering Education" 


\section{QFD Overview}

QFD is a quality improvement system for designing a product and its necessary corresponding system design elements based on customers' needs and expectations (voice of customer). It increases the focus on understanding customers' requirements, including identifying and ranking the relative importance of customer requirements. Furthermore, results of a QFD analysis can be used to prioritize the most important system design elements, enabling efforts and resources to be concentrated on improving those design elements that most effectively meet customers' needs.

Laying out customer requirements and design specifications in a matrix enables each customer requirement to be compared with each of the design specifications. Figure 1 illustrates a QFD house of quality. In the body of the matrix, symbols are entered representing the strength of the relationship between the two lists. At the roof of the house is where some of the design specifications are interrelated with each other, in terms of a positive or negative relationship. The left hand side of the matrix is where the customer requirements and the importance rating are listed. The right hand side is where the competitive analysis is listed. From this information the prioritization of each item that has the greatest potential for success will be developed and used in planning. The bottom part of the matrix shows the prioritized design specifications and how difficult it will be to achieve these successfully ${ }^{6}$. Other information that can be placed in QFD is product benchmarking data and target values.

At any stage, QFD describes the matrix of what the customer wants versus how the supplier will supply it. The first QFD matrix is used to translate customer wants (requirements of the actual end-customer) into product characteristics (broad details of how the requirements will be met). The product characteristics are then translated through another QFD matrix into part characteristics. Part characteristics are translated into process characteristics. Finally, process characteristics are translated into production controls. For the purpose of this study, the QFD process was only concerned with the development of the first two matrices.

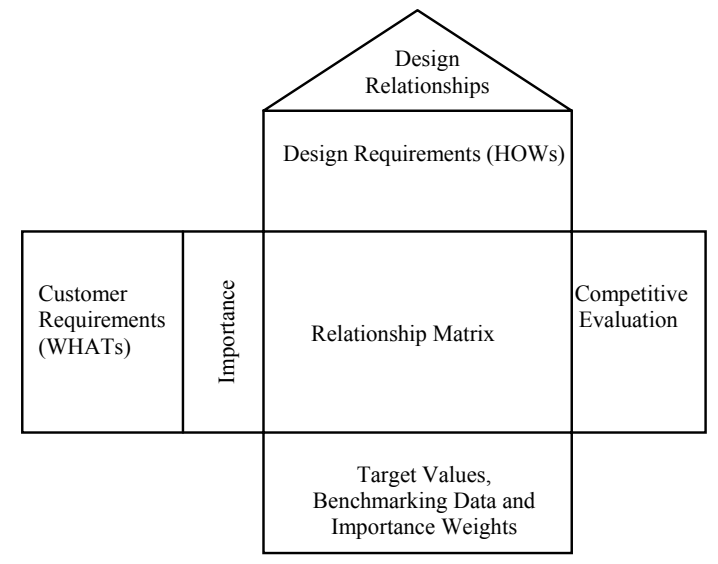

Figure 1. QFD house of quality

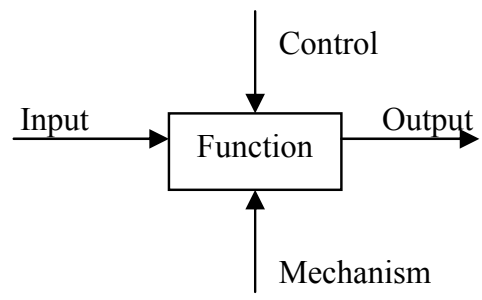

Figure 2. General elements in $\mathrm{IDEF}_{0}$ modeling approach

\section{IDEF $_{0}$ Overview}

$\mathrm{IDEF}_{0}$ is a functional modeling technique. The principle goal of $\mathrm{IDEF}_{0}$ is to provide a structured approach for breaking a complex system into more elemental components that are

"Proceedings of the 2005 American Society of Engineering Education Annual Conference \& Exposition Copyright (C) 2005, American Society for Engineering Education" 
simpler to deal with ${ }^{7}$. Each function within a system can be thought of as a process in which mechanisms transform the system from an initial state to a transformed state subject to certain controls. Each function is defined in terms of a set of inputs, outputs, mechanisms, and controls. Boxes are used to represent activities, actions, processes, functions, tasks and operations. Arrows indicate relationships or information flow among the functions. The arrows entering and leaving the boxes on the left and right represent "inputs" and "outputs" respectively. An input is something that is changed by the process. Outputs are what the inputs are transformed to. Functions transform inputs into outputs. Arrows entering from the top of the boxes are "controls" and arrows entering from the bottom are "mechanisms". Controls restrict or guide the way transformation occurs. Mechanisms are actors (humans, machines) that perform the function. Figure 2 shows general elements in an $\mathrm{IDEF}_{0}$ model.

An IDEF $_{0}$ model consists of an integrated set of diagrams. Each diagram contains more detail about a function and is linked to more general diagrams. The process of describing a function in more detail is called decomposing a function. The more general diagram is called the parent of the detailed diagram. $\mathrm{IDEF}_{0}$ models are read in a top-down manner. The top level diagram or the A-0 diagram summarizes the overall function of the system, which is represented by a single box ${ }^{8}$.

\section{QFD and IDEF 0 Models Development Process}

Based on previous research, $\mathrm{QFD}$ and $\mathrm{IDEF}_{0}$ were used in combination ${ }^{8}$. The major steps in the QFD and $\mathrm{IDEF}_{0}$ models development process are (1) the development of the first QFD matrix (2) the development of the $\mathrm{IDEF}_{0}$ models based on the information from the first step, and (3) the development of the second QFD matrix using the functions or activities defined in the $\mathrm{IDEF}_{0}$ models in step 2.

\section{(1) The development of the first QFD matrix}

The goal of this step is to elicit the requirements of the customers (WHATs) and the design elements (HOWs) through the QFD process.

Identifying potential stakeholders is the first and the most important step of the QFD process. At any point during the process a customer and supplier can be defined. The customer is the person receiving an input, which is the output of the supplier. The customer/supplier chain links all the way through the process from inception to launch and beyond ${ }^{6}$. Educational institutions often involve many stakeholders. Different classifications exist in literature. Customer does not mean only the student or the parents. These stakeholders could be internal customers, i.e. students, faculty, administrators, as well as external customers, such as community, perspective employers, other universities, accrediting agents, alumni, and donors. Each institution must determine (based on its own circumstances) how many of these are part of its customer base. For this study, customers of IME at OSU are defined as (1) internal customers who are students and faculty, and (2) external customers who are accrediting agents and perspective employers (industry).

Each group of customers has its own definition of satisfaction and each definition must be known and addressed. Various methods, e.g. interviewing, questionnaire process, brainstorming, focus group discussions, etc. can be used to determined customer requirements. Customers are asked to rate the importance of each requirement (for example on a scale 1 to 5 , where 1 represents the least importance and 5 represents the most

"Proceedings of the 2005 American Society of Engineering Education Annual Conference \& Exposition Copyright (C) 2005, American Society for Engineering Education" 
importance). These values are then averaged for each WHAT to give an overall rating. For this study, the example of the first QFD matrix for the external customers was developed (see Figure 3). The external customer requirements are defined based on three groups of external customers (1) ABET Requirements (2) Manufacturing Program Criteria, and (3) Industrial Engineering Program Criteria. A small team of external customers assign the importance values for the requirements. Figure 3 shows the QFD matrix for external customers. A QFD matrix for the internal customers can be constructed similarly.

One of the significant aspects of the QFD system is using cross-functional teams. This team is composed of students, faculty members, and potential employers. After the WHATs are found, the design requirements (HOWs) that would satisfy the WHATs must be determined by the cross-functional team. It is necessary for the cross-functional teams to also prioritize and decide which HOWs should be selected to implement. Relationships between WHATs and HOWs are determined. A correlation scale of strong (weight 5), medium (weight 3 ), and weak (weight 1) is used to describe the relationship between each design element as it intersects with each customer requirement. The prioritization of the design elements can be seen from their absolute and relative value shown in the QFD matrix.

The design element absolute value is calculated by summing the products of the importance value of each requirement and the correlation value at the intersection between that requirement and that design element. For example, in the first QFD matrix, for the design element of "Institution-industry and institution-community relationships", the absolute value was found by multiplying the importance value for the requirement of "Understanding of professional and ethical responsibility" (3) by the strong correlation value (5) to get 15. This value was then added to the value of 3 , which results from multiplying the importance value for "Board education necessary to understand the impact of engineering solutions in a global and societal context" (3) by the weak relationship value (1), the value of 2 resulted from multiplying the importance value for "Recognition of the need for, and an ability to engage in life-long learning" (2) by the weak relationship value (1), and the value of 2 resulted from multiplying the importance value for "Manufacturing competitiveness" (2) by the weak relationship value (1). The absolute result were $(3 \times 5)+(3 \times 1)+(2 \times 1)+(2 \times 1)=22$. The total absolute values were then converted to the relative rankings given in the last row of the matrix.

From the relative ranking, the top eight quality characteristics or the design elements were identified as teaching methods, students, instructor qualifications, facilities, technology and equipment, physical learning environment, curriculum design, material and institution policies, respectively. 


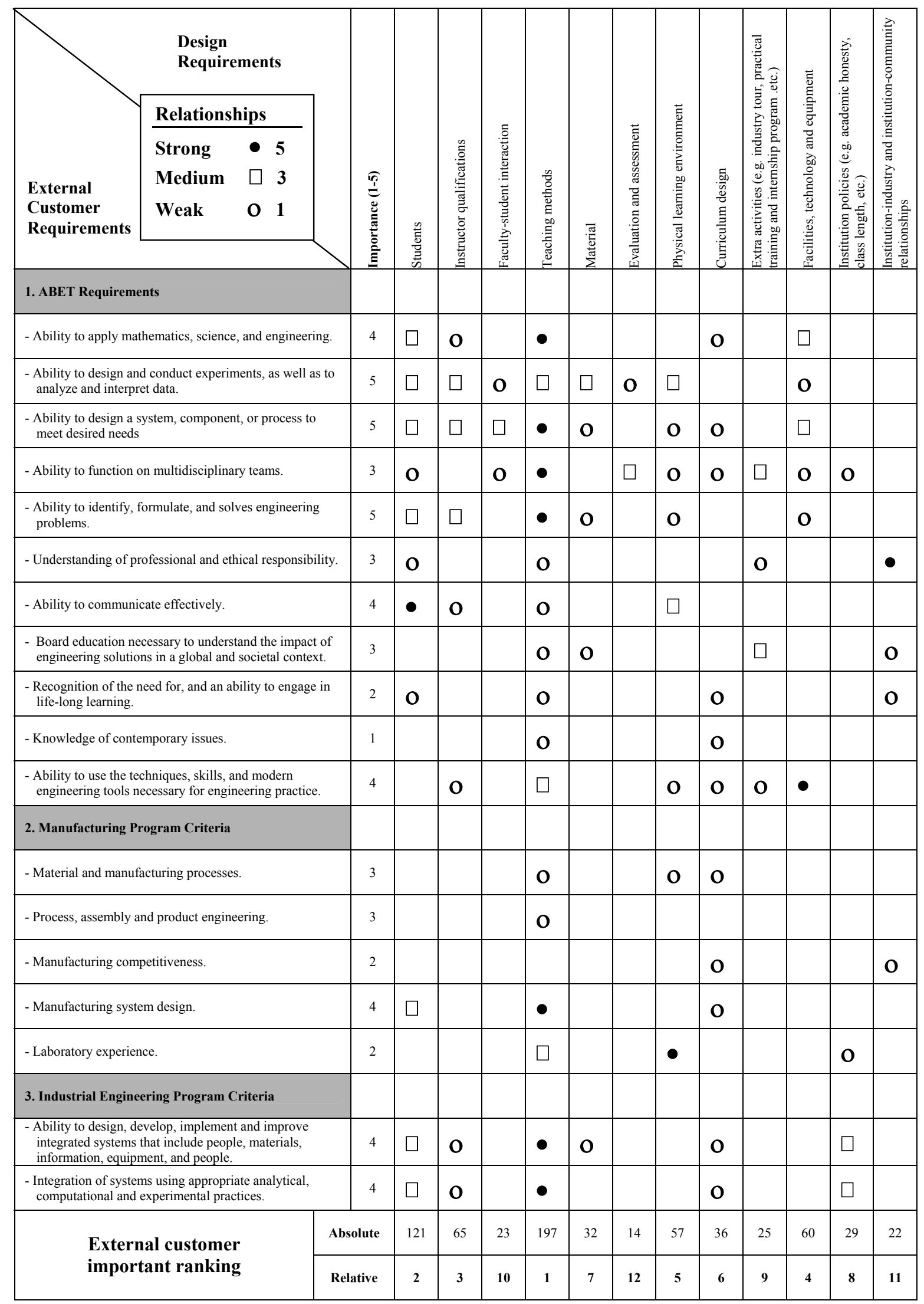

Figure 3. First QFD matrix for external customers

"Proceedings of the 2005 American Society of Engineering Education Annual Conference \& Exposition Copyright (O) 2005, American Society for Engineering Education" 


\section{(2) The development of the IDEF $F_{0}$ models}

From the first QFD matrix, the top eight quality characteristics or the design elements were identified as teaching methods, students, instructor qualifications, facilities, technology and equipment, physical learning environment, curriculum design, material and institution policies respectively. The results from QFD process can be used to prioritize the most important system design elements, enabling efforts and resources to be concentrated on improving these elements. These eight quality characteristics were then used to develop an $\mathrm{IDEF}_{0} \mathrm{~A}-0$ diagram of the instructional processes context to see the relationship among them.

In the MWT classroom instructional process, inputs are students with existing abilities, knowledge, attitudes, and technology experiences. Controls are MWT availability, usability, curriculum, other requirements and regulations (e.g. ABET criteria), institution policies (e.g. academic honesty, class length, class size, etc.), and classroom policies (syllabus, learning objectives, curriculum). Mechanisms are the physical learning environment (building, and classroom configuration), material, equipment, technology (both hardware and software), instructors, as well as other students. Students have important roles in MWT instructional processes. They are both inputs which are changed by the processes and mechanisms which perform the functions. Outputs are observable changes in abilities, knowledge, attitudes, and technology experiences in students. Figure 4 illustrates the IDEF $_{0}$ A-0 (context) node of the instructional process. In the MWT classroom instructional process, students with existing abilities, knowledge, attitudes, and technology experiences enter the system, then are transformed by the instructional process, and leave the processes with observable changes in abilities, knowledge, attitudes, and technology experiences.

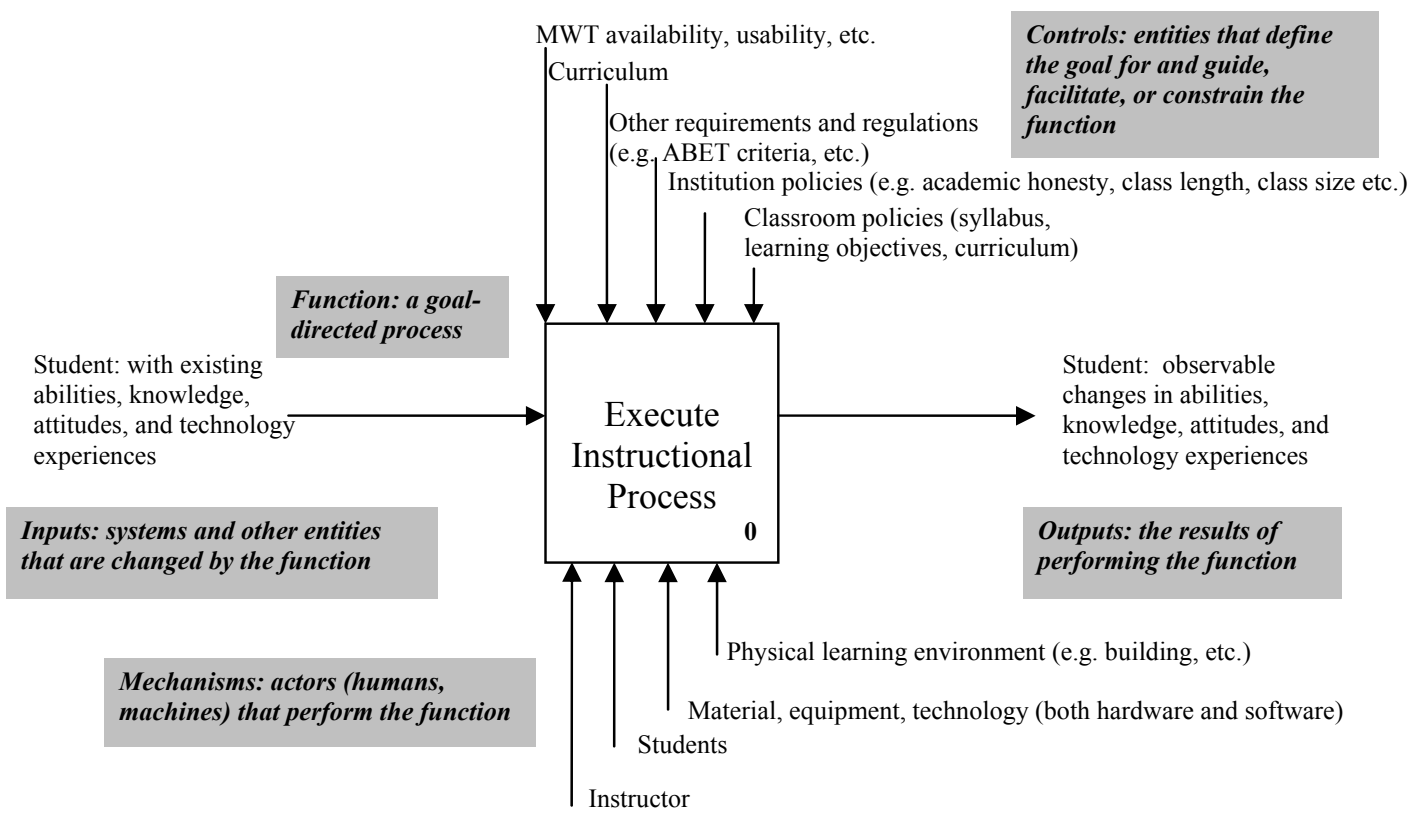

Figure 4. $\mathrm{IDEF}_{0} \mathrm{~A}-0$ diagram of the instructional processes context (From Chompu-inwai and Doolen, 2004) ${ }^{9}$

The instructional process was decomposed using the IDEF technique. The results at the A0 level are shown in Figure 5. There are five major interrelated functions at the A0 level: Plan for Instruction (A1), Perform Instruction (A2), Assess Student Performance and Achievement (A3), Evaluate Course (A4), and Determine Future Improvements (A5). There

"Proceedings of the 2005 American Society of Engineering Education Annual Conference \& Exposition Copyright (C 2005, American Society for Engineering Education" 
are also informational relationships that exist among the functions. The functions and subfunctions were decomposed further. The functional hierarchy is shown in Figure 6 to provide an overview of the final decomposition.

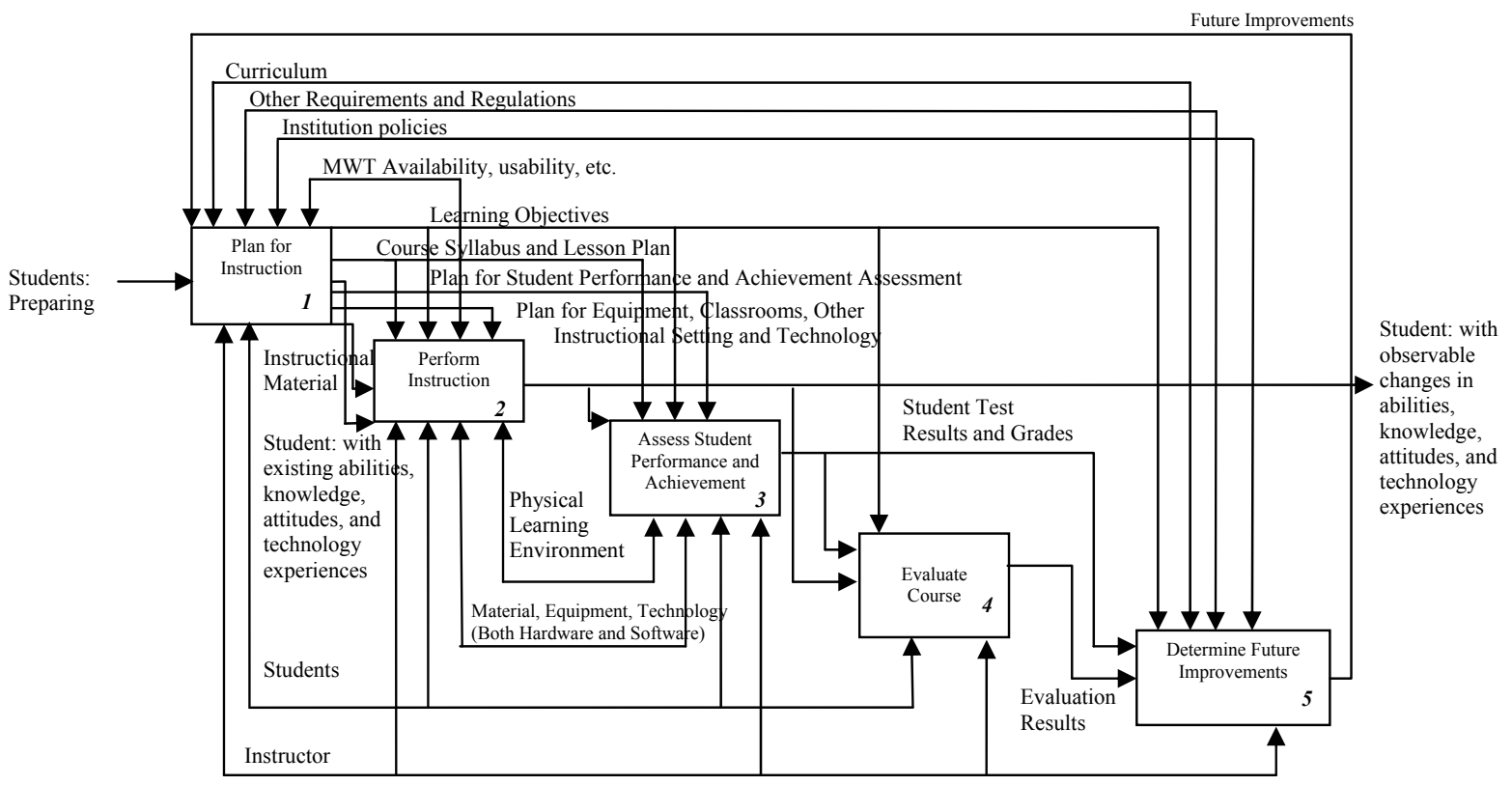

Figure 5. $\mathrm{IDEF}_{0} \mathrm{~A} 0$ diagram for the instructional processes (From Chompu-inwai and Doolen, 2004) ${ }^{9}$

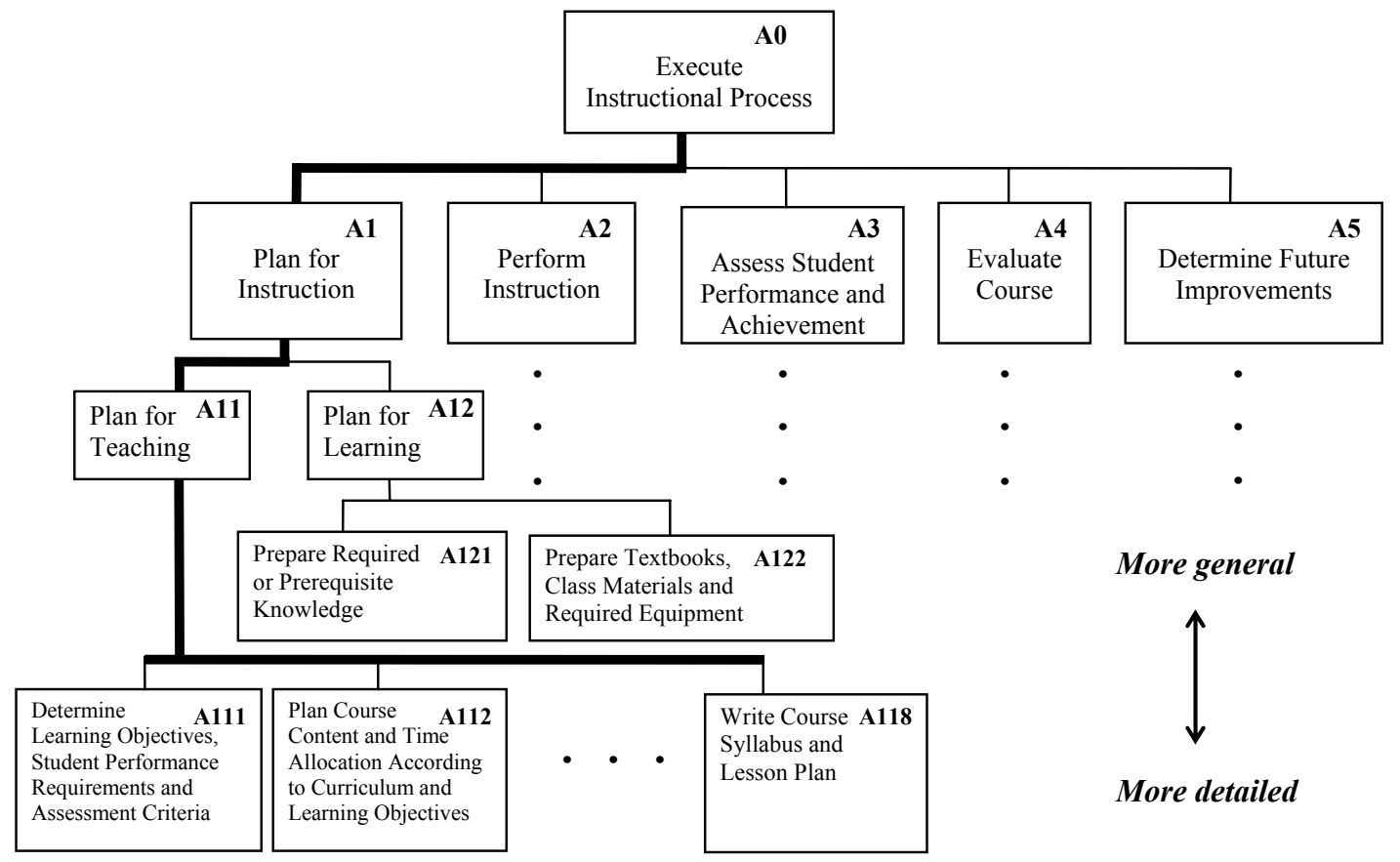

Figure 6. $\mathrm{IDEF}_{0}$ functional hierarchy for MWT classroom.

An illustrative decomposition of the A1 branch is provided

(From Chompu-inwai and Doolen, 2004) ${ }^{9}$

"Proceedings of the 2005 American Society of Engineering Education Annual Conference \& Exposition Copyright (C) 2005, American Society for Engineering Education” 


\section{(3) The development of the second QFD matrix using the functions or activities defined in the IDEF 0 models in step 2}

As mentioned earlier, for the purpose of this study, the QFD process was only concerned with the development of the first two matrices. In this step, the design requirements or the quality characteristics from the first QFD matrix were used as the WHATs in the second QFD matrix and the functions from the $\mathrm{IDEF}_{0}$ model developed in step 2 were used as the HOWs. Figures 7 and 8 show the second QFD matrices for external customers for non-MWT and MWT classrooms, respectively. These matrices show the relationships of the functions or activities with the design requirements (or quality characteristics) from the first QFD matrix. The primary purpose of these matrices is to make sure those activities or functions meet the design requirements.

Based on the non-MWT and MWT second QFD matrices, a comparison of the activities was completed. The activity of plan for instruction is more important in the MWT classroom than in the traditional lecture-based classroom. This result is consistent with previous results from the literature. In the MWT environment, the teaching pedagogy may be different from those used in a more traditional course $\mathrm{e}^{10}$. The instructor is no longer focused only on the presentation of materials; rather the instructor becomes a facilitor of learning. Instructors may have to plan and design for providing students with a collaborative situation (e.g. creating class activities and exercises), rather than only planning to present the materials as in a traditional lecture-based course. In a MWT classroom, students must also plan. As with a traditional classroom, this includes activities such as reviewing prerequisites or class materials. Students may also have to become familiar with the required MWT before coming to class and must also plan to bring the MWT devices to the classroom. The student roles in the MWT classroom are not only to absorb instructional presentations, but also to explore and participate in the learning environment ${ }^{9}$.

\section{Conclusion}

This study illustrates how QFD and $\mathrm{IDEF}_{0}$ models can be used complimentarily to identify customer requirements and provide insight on how to meet these requirements in higher education institutions. The framework described can be used for instructional process analysis for course redesign or improvement, for evaluating the existing instructional program, as well as to derive ideas on what can be done to improve existing programs to better satisfy customers.

First, the stakeholder groups were identified as internal and external customers. The first QFD matrix for external customers was illustrated using ABET requirements, Manufacturing program criteria, and Industrial Engineering program criteria as the external customer requirements. The correlation between the customer requirements and the design elements were identified. The QFD matrix pointed out the most important quality affected elements in the teaching-learning process in the IME classrooms at OSU. The question of how the design element or requirements can be achieved is answered by using the $\mathrm{IDEF}_{0}$ functional modeling technique. Furthermore, with the use of $\mathrm{IDEF}_{0}$, functions, inputs, as well as mechanisms and constraints can be identified. The design requirements or the quality characteristics from the first QFD matrix were used as the WHATs in the second QFD matrix and the functions from the $\mathrm{IDEF}_{0}$ model used as the HOWs.

This study is an example of how QFD and $\mathrm{IDEF}_{0}$ can be applied in higher education institution. For QFD and $\mathrm{IDEF}_{0}$ to be successfully implemented within other institutions,

"Proceedings of the 2005 American Society of Engineering Education Annual Conference \& Exposition Copyright (C 2005, American Society for Engineering Education" 
they must be adapted to the particular situation surrounding their use. Furthermore, the HOWs lists, importance rankings and relationships were identified based on the perceptions and judgments of a very small sample. The cross-functional work of students and staff and a larger sample may be needed for further studies and would be critical to developing more reliable customer requirements. 


\begin{tabular}{|c|c|c|c|c|c|c|c|c|c|c|c|c|c|c|c|c|c|c|c|c|}
\hline $\begin{array}{l}\text { IDEF }{ }_{0} \text { Functions } \\
\begin{array}{|lll}\text { Relationships } \\
\text { Strong } & \bullet & 5 \\
\text { Medium } & \square & 3 \\
\text { Weak } & 0 & 1 \\
& \\
\text { Design } & \\
\text { Requirements }\end{array} \\
\end{array}$ & 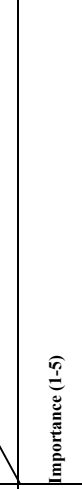 & 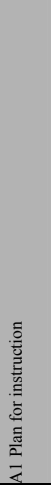 & 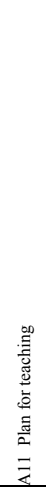 & 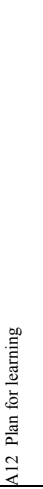 & 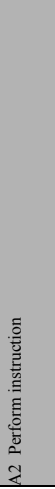 & 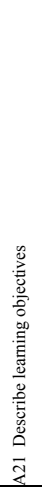 & 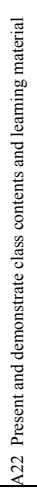 & 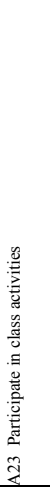 & 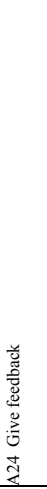 & 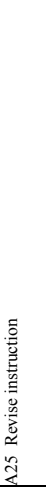 & 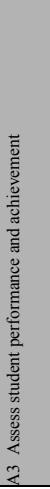 & 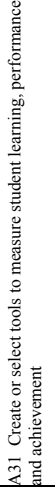 & 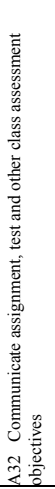 & 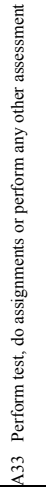 & 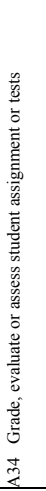 & 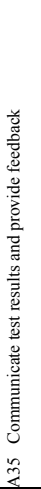 & 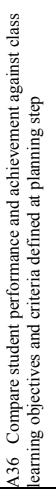 & 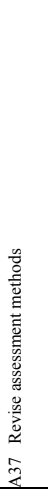 & 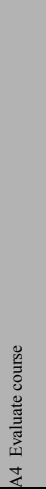 & 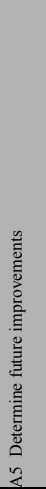 \\
\hline Teaching methods & 197 & & $\square$ & O & & $\square$ & $\square$ & $\bullet$ & & $\square$ & & $\bullet$ & $\square$ & & O & & & & & \\
\hline Students & 121 & & O & O & & & & 0 & $\bullet$ & & & O & & $\bullet$ & & & & & $\bullet$ & \\
\hline Instructor qualifications & 65 & & $\square$ & & & $\square$ & $\square$ & $\square$ & $\bullet$ & $\bullet$ & & $\square$ & & & $\square$ & o & $\square$ & $\square$ & & $\bullet$ \\
\hline $\begin{array}{l}\text { Facilities, technology and } \\
\text { equipment }\end{array}$ & 60 & & O & O & & & & O & & & & $\square$ & & $\mathrm{O}$ & & & & & & \\
\hline Physical learning environment & 57 & & $\bullet$ & & & & & $\square$ & & & & & & & & & & & & \\
\hline Curriculum design & 36 & & $\bullet$ & $\mathrm{O}$ & & & & & & & & & & & & & & & & $\bullet$ \\
\hline Material & 32 & & $\bullet$ & $\square$ & & & $\square$ & & & & & O & & & & & & & & \\
\hline Institution policies & 29 & & $\bullet$ & & & & & & & & & & & $\mathbf{O}$ & & & & & & $\square$ \\
\hline \multirow{2}{*}{ Important ranking } & Absolute & 2247 & 1737 & 510 & 5046 & 786 & 882 & 1532 & 930 & 916 & 3645 & 1513 & 591 & 694 & 392 & 65 & 195 & 195 & 605 & 592 \\
\hline & Relative & 3 & & & 1 & & & & & & 2 & & & & & & & & 4 & 5 \\
\hline
\end{tabular}

Figure 7. Second QFD matrix for external customers (for non-MWT classroom)

"Proceedings of the 2005 American Society of Engineering Education Annual Conference \& Exposition Copyright (0) 2005, American Society for Engineering Education" 


\begin{tabular}{|c|c|c|c|c|c|c|c|c|c|c|c|c|c|c|c|c|c|c|c|c|}
\hline 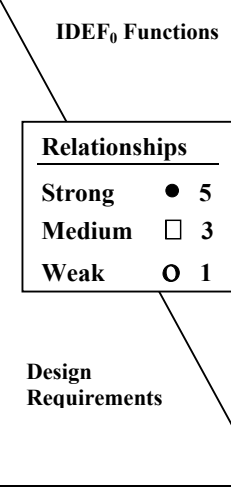 & 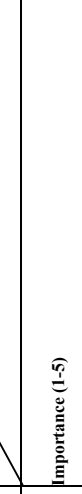 & 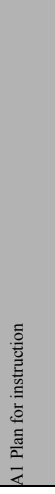 & 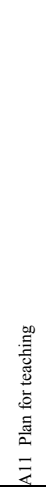 & 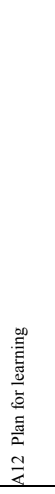 & 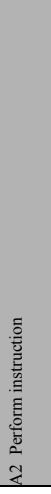 & 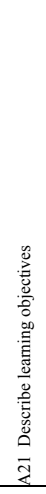 & 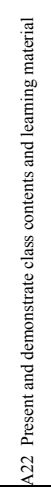 & 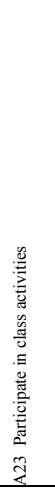 & 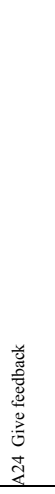 & 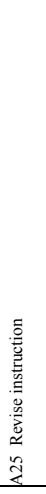 & 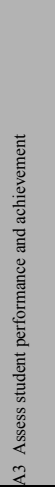 & 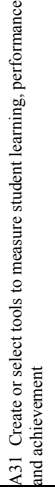 & 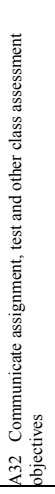 & 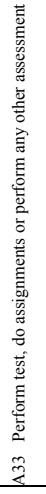 & 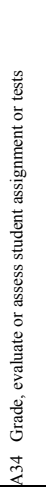 & 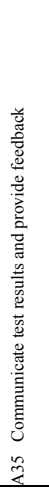 & 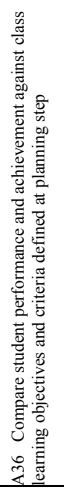 & 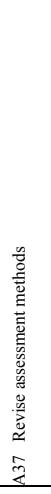 & 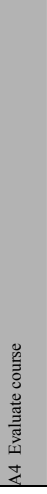 & 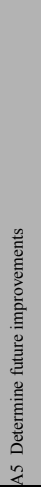 \\
\hline Teaching methods & 197 & & $\bullet$ & $\square$ & & $\square$ & $\square$ & $\bullet$ & & $\square$ & & O & $\square$ & & O & & & & & \\
\hline Students & 121 & & o & $\bullet$ & & & $\square$ & $\bullet$ & $\bullet$ & & & $\square$ & & $\bullet$ & & & & & $\bullet$ & \\
\hline Instructor qualifications & 65 & & $\bullet$ & $\bullet$ & & $\square$ & $\square$ & $\square$ & $\bullet$ & $\bullet$ & & $\square$ & & & $\square$ & o & $\square$ & $\square$ & & $\bullet$ \\
\hline $\begin{array}{l}\text { Facilities, technology and } \\
\text { equipment }\end{array}$ & 60 & & o & o & & & & $\bullet$ & $\bullet$ & & & $\square$ & $\square$ & $\square$ & & $\square$ & & & & \\
\hline Physical learning environment & 57 & & $\bullet$ & & & & & o & & & & & & & & & & & & \\
\hline Curriculum design & 36 & & $\bullet$ & O & & & & & & & & & & & & & & & & $\bullet$ \\
\hline Material & 32 & & $\bullet$ & $\square$ & & & $\square$ & & & & & O & & & & & & & & \\
\hline Institution policies & 29 & & $\bullet$ & & & & & & & & & & & O & & & & & & $\square$ \\
\hline \multirow{2}{*}{ Important ranking } & Absolute & 3974 & 2261 & 1713 & 6319 & 786 & 1245 & 2142 & 1230 & 916 & 3579 & 967 & 771 & 814 & 392 & 245 & 195 & 195 & 605 & 592 \\
\hline & Relative & 2 & & & 1 & & & & & & 3 & & & & & & & & 4 & 5 \\
\hline
\end{tabular}

Figure 8. Second QFD matrix for external customers (for MWT classroom)

"Proceedings of the 2005 American Society of Engineering Education Annual Conference \& Exposition Copyright (0) 2005, American Society for Engineering Education" 


\section{Bibliography}

1 ABET (2003, November 1). Criteria for accrediting engineering programs. Retrieved August 12, 2004, from http://www.abet.org/images/Criteria/E001\%2004-05\%20EAC\%20Criteria\%2011-20-03.pdf

2 Brackin, P., \& Rogers, G.M. (1999). Assessment and quality improvement process in engineering and engineering education. Proceedings of ASEE/IEEE Frontiers in Education Conference, Puerto Rico, 29, 11a1-21- 25.

3 Chang, I. \& Chia-hung Ku, A, (1995). Engineering and technical education in Taiwan: an observation based on TQM concept. Proceedings of ASEE Annual Conference, USA, 2414-2419.

4 Ermer, D.S. (1995, May). Using QFD becomes an educational experience for students and faculty. Quality Progress, 131-136.

5 Koksal, G., \& Egitman, A. (1998). Planning and design of industrial engineering education policy. Computers and Industrial Engineering, 35(3-4), 639-642.

6 Fox, J. (1993). Quality Through Design: The Key to Successful Product Delivery. U.K: McGraw-Hill Book Company Europe.

7 Haines, L.A. \& Evers, K. (1990). An IDEF $_{0}$ representation of the instructional system development (ISD) process-why it works. IEEE Proceedings of the National Aerospace and Electronics Conference, 2, 806-811

8 Sarkis, J. \& Liles, D.H. (1995). Using IDEF and QFD to develop an organizational decision support methodology for the strategic justification of computer-integrated technologies. International Journal of Project Management, 13(3), 177-185.

9 Chompu-inwai and Doolen, (2004). IDEF functional modeling for instructional processes in mobile wireless technology classrooms. Proceedings of the International Conference on Computers \&Industrial Engineering, USA, 34, 61-66.

10 Lowther, D.L., Ross, S.M., \& Morrison, G.R., (2001). Evaluation of a Laptop Program: Successes and Recommendations. Proceeding of National Educational Computing Conference, "Building on the Future", Chicago, IL, 1-8.

\section{Biography}

RUNGCHAT CHOMPU-INWAI is a doctoral student in the Industrial and Manufacturing Engineering Department at Oregon State University. Chompu-inwai received her B.S. in Industrial Engineering from Chiang Mai University, Thailand in 1997. She received an M.Eng.Sc. in Manufacturing Engineering majoring in Industrial Management from The University of New South Wales, Australia in 2000. Her research is focused on mobile technology use in education.

DR.TONI L.DOOLEN is an Assistant Professor in the Industrial and Manufacturing Engineering Department at Oregon State University. Dr.Doolen received a B.S. in Material Science and Engineering and a B.S. in Electrical Engineering from Cornell University in 1987. She received an M.S. in Manufacturing Systems Engineering from Stanford University in 1991. She received her Ph.D. in Industrial Engineering from Oregon State University in 2001. Her research is focused on manufacturing systems design, lean manufacturing, work group effectiveness, mobile technology in education, error management and reduction, and survey design and methodology.

"Proceedings of the 2005 American Society of Engineering Education Annual Conference \& Exposition Copyright (C) 2005, American Society for Engineering Education" 